\title{
Percutaneous endoscopic discectomy in adolescent lumbar disc herniation: a 3- to 5-year study
}

\author{
Yu Chen, MD, Ruoxian Song, PhD, Weimin Huang, PhD, and Zhengqi Chang, PhD \\ Department of Orthopedics, General Hospital of Jinan Military Commanding Region, Jinan, Shandong Province, People's \\ Republic of China
}

\begin{abstract}
OBJECTIVE The authors sought to investigate the efficiency of percutaneous endoscopic discectomy (PED) in adolescent patients with lumbar disc herniation (LDH), compare PED outcomes in adolescent patients with those in young adult LDH patients as controls, and discuss relevant technical notes.

METHODS This was a retrospective study involving 19 adolescent LDH patients (age $>13$ and < 18 years, 20 discectomies) and 38 young adults (age < 40 years, 38 discectomies) who also had LDH and were matched to the adolescent group for sex and body mass index. The combined cohort included 51 male patients $(89.5 \%)$ and 6 female patients $(10.5 \%)$, with an average age of 26.7 years (range 14-39 years). The operated levels included L3-4 in 1 patient $(1.7 \%)$, L4-5 in 22 patients (37.9\%), and L5-S1 in 35 patients (60.4\%). Two adolescents (10.5\%) exhibited apophyseal ring separation and one (5.3\%) had had previous PED. All patients underwent PED under local anesthesia. Outcomes were evaluated through a visual analog scale (VAS), the Japanese Orthopaedic Association (JOA) scoring system, and the modified MacNab grading system.
\end{abstract}

RESULTS The mean duration of follow-up was 41.7 months (range 36-65 months). The outcomes in adolescents were satisfactory and comparable with previously reported outcomes of microsurgical discectomy (MD) and conventional open discectomy (COD). The adolescent patients had a faster and better recovery course than the adult patients $(p<$ 0.01). One adolescent patient (5.3\%) exhibited recurrence and 2 adults (5.3\%) experienced transient dysesthesia; the complication rates were comparable in the 2 age groups $(p=0.47)$. Prolonged duration of symptoms $(p<0.01)$ and disc degeneration $(p=0.01$ ) were correlated with lower postoperative JOA values; patients with extrusions had higher postoperative JOA values than those with protrusions $(p=0.01)$.

CONCLUSIONS PED may yield favorable results in the treatment of adolescent LDH in terms of short- to medium-term follow-up; restricted discectomy and a conservative rehabilitation program might be advisable. Further long-term studies are warranted to address this rare disease entity.

https://thejns.org/doi/abs/10.3171/2018.8.PEDS18442

KEYWORDS intervertebral disc; discectomy; percutaneous; adolescent; minimally invasive surgical procedures; spine

$\mathrm{L}$ UMBAR disc herniation (LDH) in children and adolescents is rare, representing $0.5 \%$ to $3 \%$ of all surgically treated cases of $\mathrm{LDH} .^{3,10-12,14}$ It is recognized that this disorder relates to various factors, including trauma or intensive sports activities, ${ }^{31}$ structural malformations of the spine, ${ }^{5}$ and hereditary factors. Pediatric LDH may be distinguished from adult LDH in that more adolescent patients exhibit movement limitation during the straight leg raise test (90\%) due to greater nerve root tension than in adults. ${ }^{7,25}$
Because conservative treatment is not as effective for pediatric $\mathrm{LDH}$ as it is for adult $\mathrm{LDH},{ }^{1,19,25}$ pediatric patients with neurological deficits responding poorly to conservative treatment should undergo surgical procedures. ${ }^{20}$ Surgical modalities comprise conventional open discectomy (COD), ${ }^{28,31}$ microsurgical discectomy (MD), ${ }^{4,15,40}$ and percutaneous endoscopic discectomy (PED), $22,26,39$ but the optimal choice is controversial due to the rarity of this disease. COD may offer sufficient posterior decompression through one-sided laminotomy and limited laminec-

ABBREVIATIONS BMI = body mass index $\mathrm{COD}$ = conventional open discectomy; JOA = Japanese Orthopaedic Association; $\mathrm{LDH}=$ lumbar disc herniation; $\mathrm{MD}=$ microsurgical discectomy; $\mathrm{PED}=$ percutaneous endoscopic discectomy; VAS = visual analog scale.

SUBMITTED July 16, 2018. ACCEPTED August 15, 2018.

INCLUDE WHEN CITING Published online November 2, 2018; DOI: 10.3171/2018.8.PEDS18442. 
tomy; ${ }^{15,16}$ however, it is associated with excessive discectomy, root injury, and segmental instability, resulting in back pain and spinal degeneration. ${ }^{6}$ MD allows for a small skin incision and offers reduced traumatization, less likelihood of excessive discectomy, and limited root manipulation. ${ }^{15}$ COD and MD appear to be equally effective for pediatric patients with regard to short- to medium-term success rates (COD, 83\%-100\%;,15,24,29 MD, 98\%-100\% ${ }^{15,27}$ ), although there seems to be somewhat more difference in long-term success rates, with studies showing rates of $67 \%$ and $96 \%$ following $\mathrm{COD}^{17,29}$ and $85 \%$ and $92 \%$ after MD. ${ }^{24,34}$

PED has become an important procedure in adult LDH. The technique is characterized by a series of potential advantages, including reduced tissue trauma along the surgical access pathway, minimized epidural scarring, short hospital stays, and rapid rehabilitation. ${ }^{38}$ Previous studies found short- to medium-term success rates of PED of up to $90 \%$ in adult patients. ${ }^{6,36}$ PED performed in pediatric patients has been described less frequently but has demonstrated short-term success rates of $91 \%$ to $100 \% .^{22,26,39}$ Pediatric patients have distinctive features (more hydrated disc, less frequent degeneration, and different distribution of cells and proteoglycan synthesis) from adults and may require differential treatment, but little is known about key points of PED in pediatric cases. In this study we performed PED on adolescent LDH patients and compared medium-term outcomes with those in young adults, and we also compared our findings with previously reported findings in the literature and analyzed relevant technical notes.

\section{Methods}

The present study was approved by the Ethical Committee of the General Hospital of Jinan Military Commanding Region.

\section{Study Population}

This was a retrospective study. A total of $498 \mathrm{LDH}$ patients underwent PED from January 2012 through January 2015 in our institution. This group included 19 patients older than 13 and younger than 18 years $(3.8 \%$ of the total group) who underwent a total of 20 discectomies (1 patient had a 2-level operation). Thirty-eight adult patients (age $\geq$ 18 years and $<40$ years, sex- and body mass index [BMI]matched with the adolescent patients) were selected for comparison; these patients had undergone 1 discectomy each (38 discectomies). The 57 patients (the adolescents and the matched adult controls) included 51 male patients $(89.5 \%)$ and 6 female patients $(10.5 \%)$. The overall mean age for both groups was 26.7 years (range 14-39 years). The operated levels included L3-4 in 1 patient $(1.7 \%)$, L4-5 in 22 patients (37.9\%), and L5-S1 in 35 patients $(60.4 \%)$. A comparison of the demographic and baseline clinical characteristics of the 2 groups is shown in Table 1. There were no significant between-group differences in sex, BMI, herniated levels, type of herniation, prevalence of large herniation, or physical examination findings $(p>0.05)$. The adolescents had more frequent history of trauma or intense sports activities $(\mathrm{p}<0.01)$ and less disc degeneration $(\mathrm{p}<0.01)$, and foraminal herniations were more frequent in the adolescent group $(\mathrm{p}=0.02)$. Two adolescents presented with separation of the apophyseal ring (10.5\%), and one had had previous PED (5.3\%).

\section{Inclusion and Exclusion Criteria}

The inclusion criteria were as follows: 1) MR and CT images demonstrating a soft herniated disc, 2) patient exhibiting radicular symptoms and/or back pain consistent with imaging presentation, and 3) symptoms refractory to conservative treatment for at least 6 weeks or symptoms exceeding patient's tolerance. The exclusion criteria were patient age $\geq 40$ years, sequestration, segmental instability, degenerative spinal stenosis, cauda equina syndrome, tumor, and infection.

\section{Imaging Evaluation}

We used the Pfirrmann grading system to assess disc degeneration. ${ }^{37}$ Mild degeneration is represented by Pfirrmann grades 1 to 3 and severe changes are represented by grades 4 and 5. On axial MR images we measured the extension of the herniated disc (a) and width of the spinal canal at that level (b); a large disc herniation was defined as $(\mathrm{a} / \mathrm{b}) \times 100 \% \geq 50 \%$. The degree of herniation was assessed as bulging, protrusion, extrusion, or sequestration based on MRI findings. ${ }^{23}$ The type of herniation types was categorized as central, centrolateral, foraminal, or far lateral. ${ }^{34}$ Migration of the herniated disc fragment was classified as previously described, namely "near up," "near down," "far up," or "far down.,"23

\section{Surgical Procedure}

PED was performed under local anesthesia. 22,26,39 The patient was placed prone on a radiolucent orthopedic surgery bed. An anesthetist was on standby during operations on adolescents in case sedation was needed in these patients, because compliance is imperative for monitoring symptoms and signs. A prophylactic dose of an antibiotic agent was administered within the 30 minutes before surgery (1500 mg cefuroxime sodium, or $1200 \mathrm{mg}$ clindamycin in case of allergy to cefuroxime sodium). The entry point and surgical access pathway were determined as to C-arm views. A piercing point was verified 9-13 cm lateral to the posterior midline for a transforaminal approach, whereas interlaminar procedures required an incision 1 to $1.5 \mathrm{~cm}$ lateral to midline.

During interlaminar procedures, the needle was inserted stepwise to the lateral edge of the interlaminar window (nerve root shoulder) or to the center of the interlaminar window (nerve root axillary) under fluoroscopic guidance, and a 7- to 8-mm skin incision was made. After passing through a tapered dilator (Joimax) along the needle, the working sheath and endoscope were inserted. We used a rongeur to remove a small amount of the ligamentum flavum for targeting into the spinal canal, and a restricted laminotomy was performed accordingly. A radiofrequency probe was used to ablate epidural fat and blood vessels, and then we could differentiate critical structures in the spinal canal. Using straight/angulated forceps, we removed herniated disc fragments causing root impingement; meanwhile, free disc fragments were also excised. 
Sufficient decompression was verified by easy retraction of the nerve root. If possible, a limited discectomy preserving the inner annulus was performed in adolescents to prevent early degeneration and segmental instability. In adolescents exhibiting apophyseal ring separation, the immobile bony fragment was preserved if it was not causing radiculopathy. Radiofrequency ablation was used for fibrous ring formation. We checked the surgical field meticulously by moving the endoscope along the nerve root to verify that there was no residual compression. After endoscope removal, the incision was closed with sutures.

In transforaminal procedures, the working sheath was targeted into Kambin's triangle. Index sites were verified by anteroposterior $\mathrm{C}$-arm view (outer edge of the inferior vertebral endplate) and side view (posterior superior margin of the lower vertebral endplate). The working sheath was inserted gently, with the beveled opening pointed to the traversing root. If narrowing of the foramen impeded the surgical pathway, a trephine was used for foraminotomy; this procedure also helps improve the surgical field. Other techniques and principles applied were consistent with those used in interlaminar procedures.

\section{Treatment Outcome Evaluation}

A visual analog scale (VAS) was used for assessment of pain and Japanese Orthopaedic Association (JOA) scores for assessment of functionality pre- and postoperatively; the modified MacNab grading system was used for determining the effectiveness of treatment. ${ }^{12-14}$ Preoperative assessments and postoperative evaluations within the first year after surgery were performed in person, and assessments were conducted by telephone thereafter. Postoperative interviews were conducted at 3, 6, 12, and 24 months; additional telephone surveys were pursued at 1-year intervals.

\section{Postoperative Rehabilitation}

All patients were kept on bed rest for 24 hours and then allowed to walk with a lumbar brace. Adolescents had a late return to daily activities, with a regimen of bed rest with restricted ambulation for 1 month and gradual resumption of daily activities in accordance with their individual condition and abilities. In contrast, adults were allowed to participate in regular daily activities 2 weeks postoperatively.

\section{Statistical Analysis}

We used SPSS 13.0 software (SPSS, Inc.) for statistical analysis. Pearson's chi-square test and Fisher's exact test were used for categorical data, whereas a paired t-test and analysis of variance were used for continuous data; $\mathrm{p}<$ 0.05 indicates significance.

\section{Results}

\section{Comparison of Outcomes in Adolescents and Adults}

The average duration of follow-up was 41.7 months (range 36-65 months). All patients in both age groups underwent successful transforaminal (Fig. 1) or interlaminar PED (Table 1). According to results of the modified
TABLE 1. Comparison of baseline characteristics in adolescents and adults with LDH

\begin{tabular}{|c|c|c|c|}
\hline Characteristic & $\begin{array}{c}\text { Adolescents } \\
(n=19)\end{array}$ & $\begin{array}{l}\text { Adults } \\
(n=38)\end{array}$ & $\begin{array}{c}p \\
\text { Value }\end{array}$ \\
\hline Mean age (yrs) & 15.7 & 29.3 & $<0.01$ \\
\hline Sex & & & $>0.99$ \\
\hline Male & 17 & 34 & \\
\hline Female & 2 & 4 & \\
\hline Mean BMI $\left(\mathrm{kg} / \mathrm{m}^{2}\right)$ & 23.9 & 24.2 & 0.80 \\
\hline History of trauma or intense activities & 13 & 4 & $<0.01$ \\
\hline Mean duration of symptoms (mos) & 18.7 & 14.3 & 0.09 \\
\hline Herniated levels & & & 0.63 \\
\hline L3-4 & 0 & 1 & \\
\hline L4-5 & 7 & 15 & \\
\hline L5-S1 & 13 & 22 & \\
\hline Degree of herniation & & & 0.30 \\
\hline Protrusion & 4 & 14 & \\
\hline Extrusion & 16 & 24 & \\
\hline Sequestration & 0 & 0 & \\
\hline Type of herniation & & & 0.02 \\
\hline Central or centrolateral & 15 & 37 & \\
\hline Foraminal & 5 & 1 & \\
\hline Large herniated disc & 8 & 20 & 0.51 \\
\hline Endplate changes & 0 & 3 & $>0.99$ \\
\hline Disc degeneration & & & $<0.01$ \\
\hline None & 12 & 1 & \\
\hline Mild & 4 & 12 & \\
\hline Severe & 4 & 25 & \\
\hline Migration of extruded disc fragment & 4 & 3 & 0.27 \\
\hline Dysesthesia & 6 & 13 & 0.71 \\
\hline Weakened muscle strength & 5 & 12 & $>0.99$ \\
\hline Weakened or negative tendon reflex & 5 & 12 & 0.18 \\
\hline Positive straight leg raise test & 19 & 35 & 0.33 \\
\hline Surgical approach & & & $>0.99$ \\
\hline Posterolateral & 18 & 32 & \\
\hline Interlaminar & 2 & 6 & \\
\hline Mean length of op (mins) & 110 & 95 & 0.41 \\
\hline
\end{tabular}

MacNab grading system, in the adolescent group $10 \mathrm{pa}-$ tients $(52.6 \%)$ had excellent recovery and 9 patients $(47.4 \%)$ had good recovery and in the adult group 6 patients $(15.8 \%)$ had excellent recovery and 32 patients $(84.2 \%)$ had good recovery $(p=0.01)$. According to JOA and VAS scores, the adolescent group had more favorable functional recovery $(\mathrm{p}<0.01)$ and better leg pain relief $(\mathrm{p}<0.01)$ than the adult group (Table 2). As shown in Table 2 and Fig. 2, both age groups had significant improvements in functionality and pain relief at 3 months after surgery followed by gradual improvement in the following 3 months, with stabilization in scores after 6 months.

\section{Factors Associated With Treatment Outcomes}

Two adolescents (10.5\%) exhibited apophyseal ring 


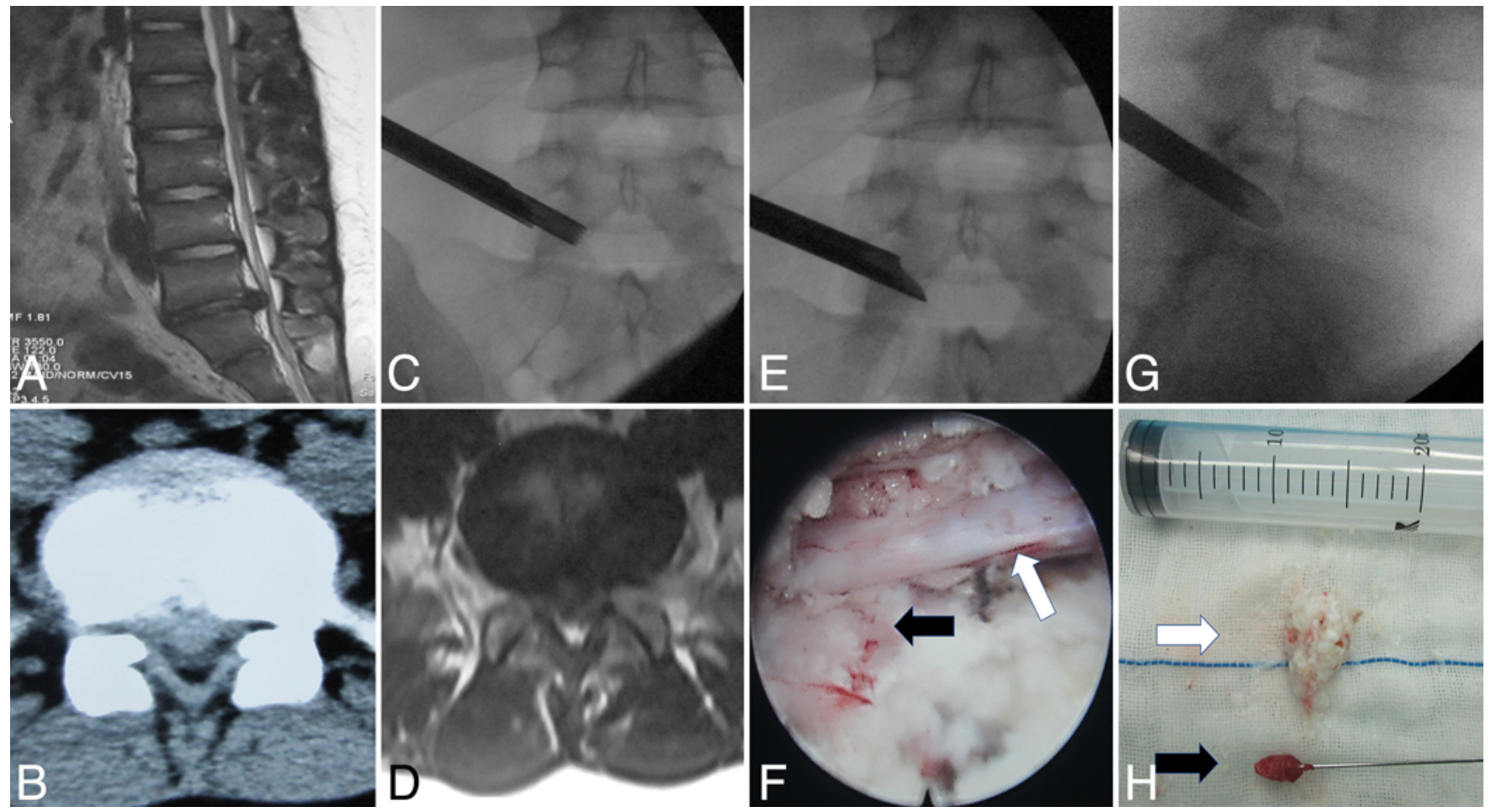

FIG. 1. Images from a representative case involving an adolescent with a herniated L5-S1 disc. This 16-year-old male patient presented with a 26 -month history of pain in his back (VAS score of 2 ) and right lower extremity (VAS score of 6 ). Physical examination showed radiculopathy consistent with the imaging findings. A, B, and D: Sagittal (A) and axial (B and D) T2-weighted MR images demonstrating a soft central disc herniation. C: Anteroposterior fluoroscopic image showing the use of a trephine to perform foraminotomy in order to ensure that the working sheath could pass via the transforaminal approach. E and G: Anteroposterior fluoroscopic images showing that the working channel was targeted to the index segment. F: Endoscopic view of the surgical field. The traversing nerve root (white arrow) was compressed by the herniated disc fragment (black arrow). $\mathrm{H}$ : Photograph of the excised disc material (white arrow) and the part of the facet removed for foraminotomy (black arrow). At 42 months after PED, the patient had an excellent outcome as measured by the MacNab grading system. Figure is available in color online only.

separation; one of these patients had an excellent recovery at 51 months and the other had a good outcome at 40 months (Fig. 3). A near down-migrated disc was found in 7 levels (12.1\%), exerting no influence on outcome ( $\mathrm{p}>$ 0.09). One adolescent patient (5.3\%) exhibited recurrence at 2 months and underwent revision PED, which resulted in good recovery at 36 months. We found no CSF leak or infection. Two adult patients (5.3\%) had transient dysesthesia and recovered. Complication rates were comparable between the 2 age groups $(p=0.47)$. There was no association between JOA values and sex $(p=0.39)$, BMI $(p=$ $0.41)$, duration of follow-up $(\mathrm{p}=0.12)$, surgical approach $(\mathrm{p}=0.81)$, operated level $(\mathrm{p}=0.12)$, endplate changes $(\mathrm{p}=$ $0.14)$, herniation type $(p=0.40)$, occurrence of large herniation $(\mathrm{p}=0.32)$, or migration of disc fragment $(\mathrm{p}=0.39)$. Lower JOA score was correlated with prolonged preoperative symptom duration $(25.2$ vs $27.2, \mathrm{p}<0.01)$ and disc degeneration ( 24.7 vs $27.1, p=0.01$ ), whereas patients with extrusions had higher JOA scores than patients with protrusions ( 25.1 vs $23.3, \mathrm{p}=0.01)$.

\section{Discussion}

\section{Outcome of PED in Adolescent LDH}

With advances in minimally invasive surgery, PED has become an important procedure for the treatment of LDH in adults, ${ }^{36,38}$ but there are few published studies of PED in pediatric patients. Lee et al..$^{22}$ performed PED in 46 adolescents and reported a success rate of $91.3 \%$ and a recurrence rate of $2.2 \%$ at a mean follow-up duration of 37.2 months; 1 patient had recurrence (rate of 2.2\%). Wang et al. ${ }^{38}$ reported good outcomes in 25 adolescent patients, with a recurrence rate of $4 \%$, but they did not report the duration of follow-up for these patients. In another study, Wang et al. ${ }^{39}$ followed 29 patients for a mean duration of 20 months; excellent outcomes were shown in 93\% patients, and unfavorable symptoms were relieved through conservative therapy. Mayer et al. ${ }^{26}$ reported a success rate of $100 \%$ in 4 cases with a mean follow-up of 2.8 years. In the present study, we reported on 19 adolescent patients with a follow-up duration of 3-5 years: 1 patient (5.3\%) exhibited recurrence and was successfully treated with revision PED, no major complications occurred, and the success rate was $100 \%$ at last follow-up. Our findings correspond to those reported in the literature. . $2,26,38,39^{2}$

The present study, although underpowered due to the rarity of LDH in adolescents, suggests adolescents might experience a quicker and better recovery course than adults after PED. A retrospective study based on the Swedish Spine Register showed similar results, with ado- 
TABLE 2. Comparison of outcomes of PED between adolescent and adult age groups

\begin{tabular}{lccr}
\hline \multicolumn{1}{c}{ Variable } & Adolescents & Adults & $p$ Value \\
\hline JOA score, mean & & & \\
\hline Preop JOA & 13.4 & 14.5 & 0.16 \\
\hline 3 mos postop & 25.9 & 21.2 & $<0.01$ \\
\hline 6 mos postop & 27.6 & 22.7 & $<0.01$ \\
\hline 12 mos postop & 28.0 & 23.4 & $<0.01$ \\
\hline 24 mos postop & 28.0 & 23.6 & $<0.01$ \\
\hline VAS score for back pain, mean & & & \\
\hline Preop & 2.9 & 2.5 & 0.39 \\
\hline 3 mos postop & 1.1 & 1.2 & 0.70 \\
\hline 6 mos postop & 0.6 & 0.7 & 0.83 \\
\hline 12 mos postop & 0.3 & 0.4 & 0.56 \\
\hline 24 mos postop & 0.3 & 0.4 & 0.56 \\
\hline VAS score for leg pain, mean & & & \\
\hline Preop & 6.8 & 6.4 & 0.34 \\
\hline 3 mos postop & 1.0 & 2.0 & $<0.01$ \\
\hline 6 mos postop & 0.2 & 1.4 & $<0.01$ \\
\hline 12 mos postop & 0.1 & 1.3 & $<0.01$ \\
\hline 24 mos postop & 0.1 & 1.3 & $<0.01$ \\
\hline
\end{tabular}

Both age groups showed improvement in JOA and VAS scores. The mean VAS score for back pain was comparable in the 2 age groups $(p>0.05)$. At last follow-up, the adolescent group showed better functionality $(p<0.01)$ and leg pain relief $(p<0.01)$ lescent patients being more satisfied with isolated discectomy outcomes at short-term follow-up. ${ }^{20}$ This might be associated with the finding that disc degeneration and facet joint changes (which are more frequent in adults) are correlated with back pain and influence discectomy outcomes. ${ }^{22}$ The present study showed that disc degeneration was associated with inferior functionality, which is consistent with reports in the literature. The adolescents in this study complied with a prudent rehabilitation program that is based on the high recurrence incidence of 20\%-30\% previously observed in this age group..$^{21,39}$ The intervertebral disc in adolescents is usually hydrated, rubbery, and viscous ${ }^{22}$ which may predispose to LDH recurrence. Delayed return to physical activities might help prevent excessive mobility of the spine and decrease downward pressure on the disc before the annulus ring heals.

\section{Comparison of Outcomes of PED, MD, and COD}

The long-term prognosis for adolescent LDH patients is at least in part dependent on tissue trauma from the surgical procedure. ${ }^{23,37}$ Table 3 presents data on the effectiveness of different procedures in pediatric LDH. COD and MD have comparable mid- to long-term success rates (83\%-100\% vs $98 \%-100 \%) .9,15,16,24,28-31,34$ PED may offer minimized trauma to the surgical pathway, and paraspinal structures, especially ligamentum flavum (associated with back pain) are well preserved ${ }^{40}$ this should theoretically improve long-term outcomes. To date, a few short-term
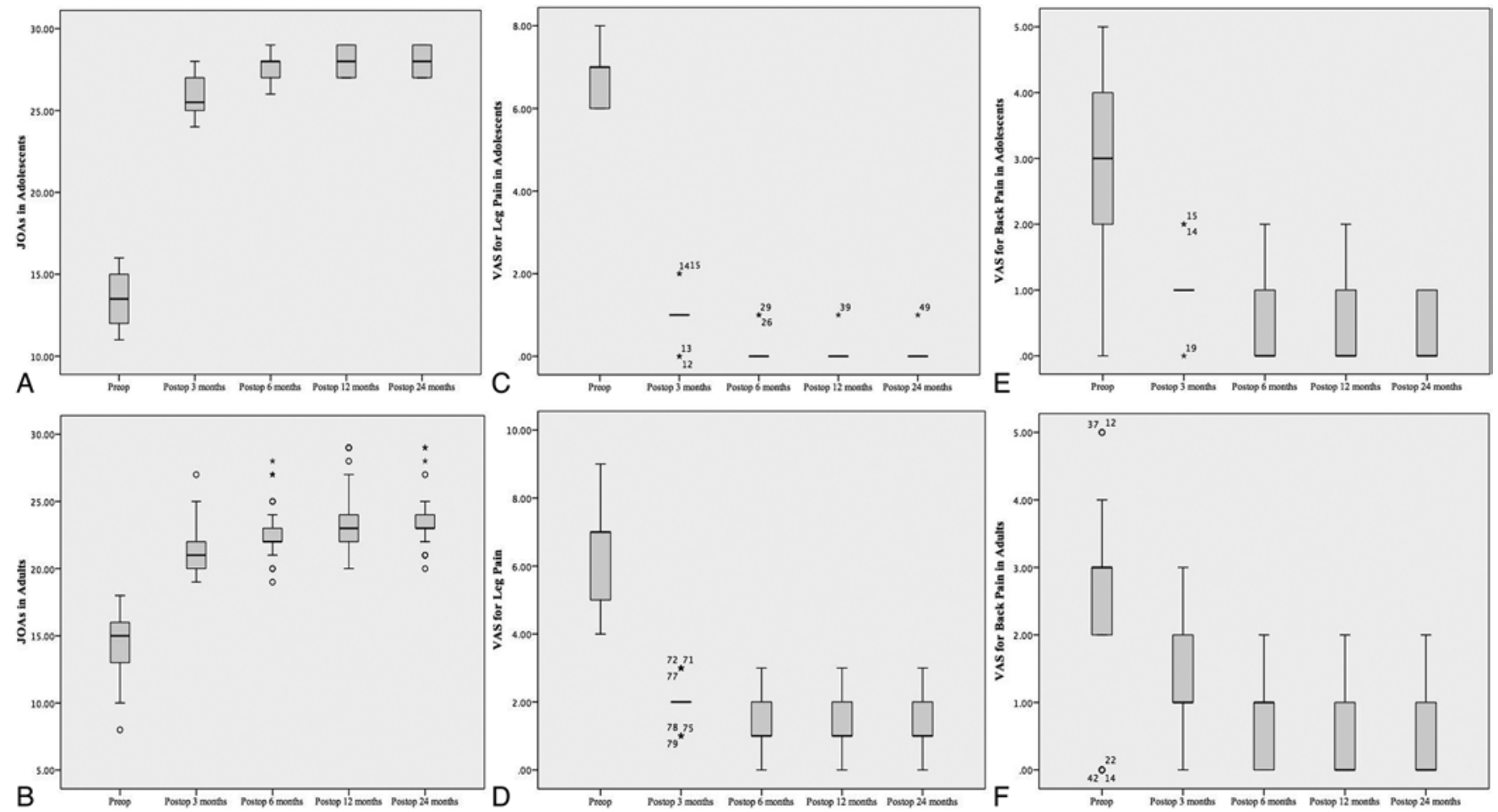

FIG. 2. Comparison of outcomes of PED in adolescent and adult age groups. A and B: Preoperative and postoperative JOA scores in the adolescent $(A)$ and adult $(B)$ groups. The adolescents had higher postoperative JOA scores than the adult group ( $p$ $<0.01$ ). JOAs = JOA scores. C and D: Preoperative and postoperative VAS scores for leg pain in the adolescent (C) and adult (D) groups. The adolescent patients had more satisfactory improvement in VAS scores for leg pain $(p<0.01)$. E and F: Preoperative and postoperative VAS scores for back pain in the adolescent $(E)$ and adult $(F)$ groups showing comparable improvement in the 2 groups $(p>0.05)$. Overall, both groups exhibited significant improvement in functionality and pain relief $(p<0.01)$. 

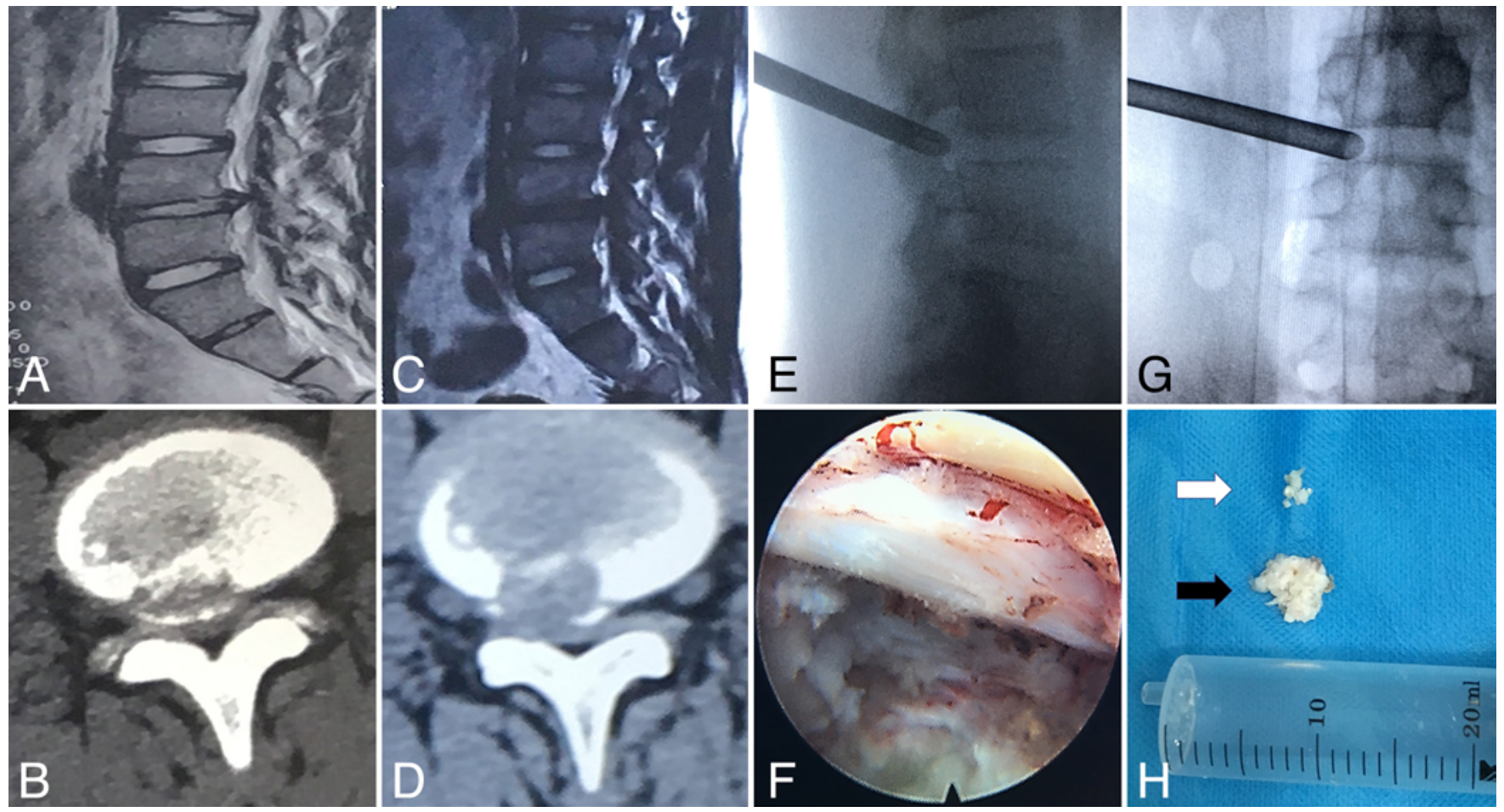

FIG. 3. Images from a case involving an adolescent who underwent a revision PED. This 16-year-old male patient presented with back pain (VAS score of 3) and pain in his right leg (VAS score of 7) 6 months after a previous PED procedure that was performed at another institution. Physical examination revealed numbness in the right calf, and the results of a straight leg raise test were positive. A and B: Sagittal T2-weighted MR image (A) and axial CT image (B) obtained before the patient's initial PED procedure demonstrating a centrolateral L4-5 disc herniation. C: Sagittal T2-weighted MR image obtained at the time of presentation to our institution (6 months after the initial surgery) indicating severe degeneration and recurrence. D: Axial CT image obtained 6 months after the initial surgery after the primary operation showing a residual bony fragment at the surgically treated level. E and G: Lateral (E) and anteroposterior (G) fluoroscopic images obtained during revision PED through the transforaminal approach. F: Endoscopic view of the surgical field. The nerve root was fully decompressed. $\mathrm{H}$ : Photograph of the excised disc fragment (black arrow) and the removed mobile bony fragment (white arrow) shown next to a $20-\mathrm{ml}$ syringe for scale. At 40 months after surgery, the patient had a good outcome as measured by the MacNab grading system. Figure is available in color online only.

studies with restricted sample size have shown success rates ranging from $91.3 \%$ to $100 \% .^{22,26,39}$ In the current study, 3- to 5-year follow-up revealed a success rate of $94.7 \%$; this is consistent with the results of COD and MD in the literature. ${ }^{22,26,27,33,35,39}$ Long-term studies have shown that the cumulative recurrence rate of isolated discectomy increases over time (Table 3), ${ }^{22}$ but no study offers longterm outcomes of PED in adolescents. Whether PED leads to results different from other procedures warrants further research.

\section{Key Points of PED in Pediatric Patients}

One crucial question regarding the use of PED in pediatric patients is how much disc should be removed. Insufficient discectomy may lead to treatment failure, whereas excessive discectomy is associated with iatrogenic instability and rapid degeneration. ${ }^{32}$ Because of unique characteristics in the pediatric population, surgical procedures in these patients may be different, but few studies have looked at the optimal extent of discectomy in pediatric LDH. Previous reports suggest that the topographical variation in chondrocyte activity and proteoglycan synthesis within the annulus fibrosus changes with age; in adults, the most active cells are located in the midannulus region, whereas in children, cells in the inner annulus were found to be most active..$^{1}$ These findings imply that discectomy in adolescents should maintain integrity of the inner annulus, which might be crucial for regeneration of disc. ${ }^{1}$ Kuroki et al. ${ }^{18}$ argued that discectomy should not stop until there is no free disc fragment or root impingement, but limited discectomy is important for preserving disc function. We performed limited discectomy in adolescents. The primary purpose was to release the root and to remove free fragments. The scope of discectomy was restrained to a small volume, with forceps advanced only short distances so that the inner annulus could be preserved. Although large extrusion can stymie this intention to some extent, surgeons may still employ restricted procedures in order to preserve the capability of disc regeneration.

This study addresses the medium-term outcome of PED in adolescents, which was rarely included in previous reports. The association between outcome and age implies possible effects of aging on the results of PED. Given that there may be unique physiological features in adolescents' discs and a lengthy postoperative recuperative period predisposes to unfavorable long-term outcome, we argue that procedures for them should be distinctive and protective.

This study is subject to several limitations, including 1) 
TABLE 3. Representative literature regarding outcomes of different surgical procedures in pediatric LDH

\begin{tabular}{|c|c|c|c|c|c|}
\hline Authors \& Year & $\begin{array}{c}\text { No. } \\
\text { of } \\
\text { Pts }\end{array}$ & Age $(y r s)^{*}$ & Op & $\begin{array}{l}\text { Follow-Up } \\
\text { (yrs) }{ }^{*}\end{array}$ & $\begin{array}{l}\text { Success } \\
\text { Rate } \\
(\%)\end{array}$ \\
\hline Ozgen et al., 2007 & 17 & $\begin{array}{l}\text { Range } \\
\quad 13-17\end{array}$ & MD & Mean 5 & 100 \\
\hline Luukkonen et al., 1997 & 12 & Mean 14.3 & MD & Mean 6 & 92 \\
\hline Silvers et al., 1994 & 10 & $<21$ & MD & $\begin{array}{l}\text { Mean } \\
\quad 10.5\end{array}$ & 85 \\
\hline $\begin{array}{l}\text { Beks \& ter Weeme, } \\
\quad 1975\end{array}$ & 43 & $\begin{array}{l}\text { Range: } \\
11-18\end{array}$ & COD & Mean 2 & 100 \\
\hline Gennuso et al., 1992 & 77 & $\begin{array}{c}\text { Mean 16; } \\
\text { range } \\
10-18\end{array}$ & COD & Mean 8.2 & 97 \\
\hline $\begin{array}{l}\text { DeOrio \& Bianco, } \\
1982\end{array}$ & 50 & $\begin{array}{c}\text { Mean 15; } \\
\text { range } \\
11-16\end{array}$ & COD & $\begin{array}{c}\text { Mean 19; } \\
\text { range } \\
5-30\end{array}$ & 73.5 \\
\hline $\begin{array}{l}\text { Papagelopoulos et al., } \\
\quad 1998\end{array}$ & 72 & $<16$ & COD & $\begin{array}{c}\text { Mean } 28 ; \\
\text { range } \\
12-45\end{array}$ & 67 \\
\hline Wang et al., 2014 & 29 & $\begin{array}{c}\text { Mean 16.4; } \\
\text { range } \\
13-18\end{array}$ & PED & Mean 1.5 & 93 \\
\hline Mayer et al., 1996 & 4 & $\begin{array}{c}\text { Mean 13; } \\
\text { range } \\
8-17\end{array}$ & PED & $\begin{array}{c}\text { Mean 2.8; } \\
\text { range } \\
1-5\end{array}$ & 100 \\
\hline Lee et al., 2006 & 46 & $\begin{array}{c}\text { Mean } 16.5 \\
\text { range } \\
13-18\end{array}$ & PED & $\begin{array}{c}\text { Mean 3; } \\
\text { range } \\
2-4\end{array}$ & 91 \\
\hline
\end{tabular}

$\mathrm{COD}=$ conventional open discectomy $; \mathrm{MD}=$ microsurgical discectomy; $\mathrm{PED}=$ percutaneous endoscopic discectomy; pts = patients.

* Authors used various descriptive statistics for patient age and duration of follow-up. If either the range or a measure of central tendency is not presented here it means that the data were not available.

lack of a nonsurgically treated group, 2) lack of long-term follow-up, and 3) single-center design with limited sample size. Long-term multicenter studies with large sample sizes are warranted to analyze the effectiveness of PED in the pediatric population.

\section{Conclusions}

Our medium-term follow-up results suggest that PED is a safe and effective procedure for the treatment of $\mathrm{LDH}$ in adolescents, with outcomes that might be comparable to those achieved with MD and COD, and that adolescents may have better outcomes than adults. Limited discectomy and a prudent rehabilitation program may be advisable. Long-term studies with large sample sizes are warranted to draw a firm conclusion.

\section{References}

1. Bayliss MT, Johnstone B, O’Brien JP: 1988 Volvo award in basic science. Proteoglycan synthesis in the human intervertebral disc. Variation with age, region and pathology. Spine (Phila Pa 1976) 13:972-981, 1988
2. Beks JW, ter Weeme CA: Herniated lumbar discs in teenagers. Acta Neurochir (Wien) 31:195-199, 1975

3. Bhatia NN, Chow G, Timon SJ, Watts HG: Diagnostic modalities for the evaluation of pediatric back pain: a prospective study. J Pediatr Orthop 28:230-233, 2008

4. Choi G, Lee SH, Deshpande K, Choi H: Working channel endoscope in lumbar spine surgery. J Neurosurg Sci 58:77-85, 2014

5. Dang L, Chen Z, Liu X, Guo Z, Qi Q, Li W, et al: Lumbar disk herniation in children and adolescents: the significance of configurations of the lumbar spine. Neurosurgery 77:954-959, 2015

6. Dang L, Liu Z: A review of current treatment for lumbar disc herniation in children and adolescents. Eur Spine J 19:205214, 2010

7. DeLuca PF, Mason DE, Weiand R, Howard R, Bassett GS: Excision of herniated nucleus pulposus in children and adolescents. J Pediatr Orthop 14:318-322, 1994

8. DeOrio JK, Bianco AJ Jr: Lumbar disc excision in children and adolescents. J Bone Joint Surg Am 64:991-996, 1982

9. Durham SR, Sun PP, Sutton LN: Surgically treated lumbar disc disease in the pediatric population: an outcome study. $\mathbf{J}$ Neurosurg 92 (1 Suppl): 1-6, 2000

10. Epstein JA, Lavine LS: Herniated lumbar intervertebral discs in teenage children. J Neurosurg 21:1070-1075, 1964

11. Feldman DS, Hedden DM, Wright JG: The use of bone scan to investigate back pain in children and adolescents. J Pediatr Orthop 20:790-795, 2000

12. Garrido E, Humphreys RP, Hendrick EB, Hoffman HJ: Lumbar disc disease in children. Neurosurgery 2:22-26, 1978

13. Gennuso R, Humphreys RP, Hoffman HJ, Hendrick EB, Drake JM: Lumbar intervertebral disc disease in the pediatric population. Pediatr Neurosurg 18:282-286, 1992

14. Grobler LJ, Simmons EH, Barrington TW: Intervertebral disc herniation in the adolescent. Spine (Phila Pa 1976) 4:267-278, 1979

15. Kuh SU, Kim YS, Cho YE, Yoon YS, Jin BH, Kim KS, et al: Surgical treatments for lumbar disc disease in adolescent patients; chemonucleolysis/microsurgical discectomy/PLIF with cages. Yonsei Med J 46:125-132, 2005

16. Kumar R, Kumar V, Das NK, Behari S, Mahapatra AK: Adolescent lumbar disc disease: findings and outcome. Childs Nerv Syst 23:1295-1299, 2007

17. Kurihara A, Kataoka O: Lumbar disc herniation in children and adolescents. A review of 70 operated cases and their minimum 5-year follow-up studies. Spine (Phila Pa 1976) 5:443-451, 1980

18. Kuroki H, Goel VK, Holekamp SA, Ebraheim NA, Kubo S, Tajima N: Contributions of flexion-extension cyclic loads to the lumbar spinal segment stability following different discectomy procedures. Spine (Phila Pa 1976) 29:E39-E46, 2004

19. Kurth AA, Rau S, Wang C, Schmitt E: Treatment of lumbar disc herniation in the second decade of life. Eur Spine $\mathbf{J}$ 5:220-224, 1996

20. Lagerbäck T, Elkan P, Möller H, Grauers A, Diarbakerli E, Gerdhem P: An observational study on the outcome after surgery for lumbar disc herniation in adolescents compared with adults based on the Swedish Spine Register. Spine J 15:1241-1247, 2015

21. Lavelle WF, Bianco A, Mason R, Betz RR, Albanese SA: Pediatric disk herniation. J Am Acad Orthop Surg 19:649656,2011

22. Lee DY, Ahn Y, Lee SH: Percutaneous endoscopic lumbar discectomy for adolescent lumbar disc herniation: surgical outcomes in 46 consecutive patients. Mt Sinai J Med 73:864-870, 2006

23. Lee S, Kim SK, Lee SH, Kim WJ, Choi WC, Choi G, et al: Percutaneous endoscopic lumbar discectomy for migrated 
disc herniation: classification of disc migration and surgical approaches. Eur Spine J 16:431-437, 2007

24. Luukkonen M, Partanen K, Vapalahti M: Lumbar disc herniations in children: a long-term clinical and magnetic resonance imaging follow-up study. Br J Neurosurg 11:280-285, 1997

25. Matsui H, Kitagawa H, Kawaguchi Y, Tsuji H: Physiologic changes of nerve root during posterior lumbar discectomy. Spine (Phila Pa 1976) 20:654-659, 1995

26. Mayer HM, Mellerowicz H, Dihlmann SW: Endoscopic discectomy in pediatric and juvenile lumbar disc herniations. J Pediatr Orthop B 5:39-43, 1996

27. Montejo JD, Camara-Quintana JQ, Duran D, Rockefeller JM, Conine SB, Blaise AM, et al: Tubular approach to minimally invasive microdiscectomy for pediatric lumbar disc herniation. J Neurosurg Pediatr 21:449-455, 2018

28. Ozgen S, Konya D, Toktas OZ, Dagcinar A, Ozek MM: Lumbar disc herniation in adolescence. Pediatr Neurosurg 43:77-81, 2007

29. Papagelopoulos PJ, Shaughnessy WJ, Ebersold MJ, Bianco AJ Jr, Quast LM: Long-term outcome of lumbar discectomy in children and adolescents sixteen years of age or younger. $\mathbf{J}$ Bone Joint Surg Am 80:689-698, 1998

30. Ruetten S, Komp M, Merk H, Godolias G: Recurrent lumbar disc herniation after conventional discectomy: a prospective, randomized study comparing full-endoscopic interlaminar and transforaminal versus microsurgical revision. J Spinal Disord Tech 22:122-129, 2009

31. Sarma P, Thirupathi RT, Srinivas D, Somanna S: Adolescent prolapsed lumbar intervertebral disc: Management strategies and outcome. J Pediatr Neurosci 11:20-24, 2016

32. Shillito J Jr: Pediatric lumbar disc surgery: 20 patients under 15 years of age. Surg Neurol 46:14-18, 1996

33. Shirado O, Yamazaki Y, Takeda N, Minami A: Lumbar disc herniation associated with separation of the ring apophysis: is removal of the detached apophyses mandatory to achieve satisfactory results? Clin Orthop Relat Res (431):120-128, 2005

34. Silvers HR, Lewis PJ, Clabeaux DE, Asch HL: Lumbar disc excisions in patients under the age of 21 years. Spine (Phila Pa 1976) 19:2387-2392, 1994

35. Thomas JG, Hwang SW, Whitehead WE, Curry DJ, Luerssen
TG, Jea A: Minimally invasive lumbar microdiscectomy in pediatric patients: a series of 6 patients. J Neurosurg Pediatr 7:616-619, 2011

36. Tu Z, Li YW, Wang B, Lü G, Li L, Kuang L, et al: Clinical outcome of full-endoscopic interlaminar discectomy for single-level lumbar disc herniation: a minimum of 5-year follow-up. Pain Physician 20:E425-E430, 2017

37. Urrutia J, Besa P, Campos M, Cikutovic P, Cabezon M, Molina M, et al: The Pfirrmann classification of lumbar intervertebral disc degeneration: an independent inter- and intraobserver agreement assessment. Eur Spine J 25:2728-2733, 2016

38. Wang H, Cheng J, Xiao H, Li C, Zhou Y: Adolescent lumbar disc herniation: experience from a large minimally invasive treatment centre for lumbar degenerative disease in Chongqing, China. Clin Neurol Neurosurg 115:1415-1419, 2013

39. Wang X, Zeng J, Nie H, Chen G, Li Z, Jiang H, et al: Percutaneous endoscopic interlaminar discectomy for pediatric lumbar disc herniation. Childs Nerv Syst 30:897-902, 2014

40. Yoshimoto M, Takebayashi T, Ida K, Tanimoto K, Yamashita T: Microendoscopic discectomy in athletes. J Orthop Sci 18:902-908, 2013

\section{Disclosures}

The authors report no conflict of interest concerning the materials or methods used in this study or the findings specified in this paper.

\section{Author Contributions}

Conception and design: Song, Chen. Acquisition of data: Song, Chen. Analysis and interpretation of data: Chen. Drafting the article: Chen. Critically revising the article: Chen. Reviewed submitted version of manuscript: Chen. Statistical analysis: Chen. Administrative/technical/material support: Song, Huang, Chang.

\section{Correspondence}

Ruoxian Song: General Hospital of Jinan Military Commanding Region, Jinan, Shandong Province, China. zhongguozhiwangcy@163.com. 